\title{
Gênero: Uma identidade em construção
}

Daniela Nunes

Resumo: $O$ presente artigo pretende trazer algumas considerações acerca da relação entre gênero e sexualidade, em um processo contínuo de mudança que sustenta a sociedade e suas relações, tomando como mote central o conceito de cultura e as contribuições da Antropologia. Assim, destacamos a relevância do contexto sociocultural e político na formação do caráter identitário do sujeito, para além de qualquer tentativa de enquadramento limitador.

Palavras-Chave: Antropologia; Cultura; Identidade.

Abstract: This article aims to bring some considerations about the relationship between gender and sexuality, in a continuous process of change that underpins society and their relations, taking as motto the central concept of culture and the contributions of anthropology. Thus, we highlight the relevance of sociocultural and political context in shaping the identity of the subject character, beyond any attempt to frame limiter.

Keywords: Anthropology, Culture, Identity.

\footnotetext{
* Mestre em História pela Universidade de Brasília. Atualmente é professora da rede estadual de educação do Estado de Goiás.
} 
Quando o homem atribuía um sexo a todas as coisas, não via nisso um jogo, mas acreditava ampliar seu entendimento: - só muito mais tarde descobriu, e nem mesmo inteiramente ainda hoje, a enormidade desse erro. De igual modo o homem atribuiu a tudo o que existe uma relação moral, jogando sobre os ombros do mundo o manto de uma significação ética. Um dia, tudo isso não terá nem mais nem menos valor do que possui hoje a crença no sexo masculino ou feminino do Sol. (Nietzsche, 2008:27).

Há muito que as questões relacionadas à sexualidade ganharam lugar de debate nos mais distintos campos do saber; das práticas para os espaços oficiais ou não; centros acadêmicos, ordenamentos jurídicos, canais midiáticos, circuitos sociais, escolares, domésticos e mesmo religiosos. O alvorecer do século XXI acena a uma nova postura frente às manifestações que se tornam a cada contemplar, ainda mais convidativas.

A segunda metade do século XX, os anos que se seguiram ao choque e horror das atrocidades cometidas nos campos de batalhas das duas grandes guerras, das dilacerações de indivíduos inseridos em uma dada condição cultural, ou da tentativa de um grupo em impor uma hegemonia racial, trouxe à tona velhas questões, contendas que se tornaram urgentes, minorias que assumiram uma postura diferenciada e que, timidamente, exigiu uma reorganização do social, uma reescrita da história.

O século XX - com seus campos de concentração e esquadrões da morte, seu militarismo e duas guerras mundiais, sua ameaça de aniquilação nuclear e sua experiência de Hiroshima e Nagasaki - certamente deitou por terra esse otimismo (do Iluminismo). Pior ainda, há a suspeita de que o projeto do iluminismo estava fadado a voltar-se contra si mesmo e transformar a busca de emancipação humana num sistema de opressão universal em nome da libertação humana. (HARVEY, 2005: 23-24).

Não apenas o clamor dos oprimidos ou a releitura do discurso dos opressores, mas a fala de novos agentes, personagens que entraram em cena e que roubaram a cena nesse início de século. Embora não sejam inovadores em suas vivências e experiências o são em seus novos arranjos discursivos, novas estratégias de atuação e de, também, imposição. O sentir, o pulsar, os medos e desejos, sempre estiveram presentes, porém, foram, quase sempre, silenciados.

Esse movimento, explícito e latente no mundo do pós-guerra, seria provocado por uma crise geral dos paradigmas, especialmente concentrado nas críticas que se seguiram ao cenário político de até então, de relações de poder construídas para além das instituições convencionais, o deslocamento do interesse da vida pública para a vida privada, com ênfase não mais em grandes personalidades e datas, mas em pessoas e acontecimentos comuns. 
Chamemos nosso tempo pela já desgastada fórmula da "crise dos paradigmas", que questionou as verdades e os modelos explicativos do real, ou entendamos nosso mundo pelo recente enfoque da globalização, dotado hoje de forte apelo, o que parece evidente é que nos situamos no meio de uma complexificação e estilhaçamento da realidade, onde é preciso encontrar novas formas de acesso para compreendê-la. A rigor, cada geração se coloca problemas e ensaia respostas para respondê-los, valendo-se para isso de um arsenal de conceitos que se renova no tempo. (PESAVENTO, 2006: 02)

Uma voz não mais tímida e velada, mutilada e dilacerada, calada e violentada, mas que ganha às ruas das grandes metrópoles, as praças das pequenas cidades, as novelas de horário nobre e folhetins juvenis.

Ao contrário do que se pode julgar o senso comum, frente aos coloridos em exposição; a reivindicação é antiga, a pressão por uma flexibilização dentro de uma normalidade alheia a qualquer desvio, ainda que as curvas sejam elas mesmas inerentes ao próprio indivíduo, ecoam ecos de tempos primordiais.

Há mais de meio século Simone de Beauvoir sacudiu os meios acadêmicos e os espíritos mais acomodados quando pronunciou em alto e bom tom a frase "Ninguém nasce mulher, torna-se mulher" (BEAUVOIR, 1980:26.) Mulheres de diferentes posições sociais, militantes ou não, passaram a pronunciá-la como um libelo contra a opressão e imposição de uma sociedade machista, conservadora e há muito ultrapassada.

Partimos do reconhecimento de que em uma sociedade e as relações que a sustentam encontra-se em processo contínuo de mudança, porém, é inegável a presença das transformações no tempo presente. No ocidente, essa nova postura é sentida e debatida pelos mais diversos grupos sociais. Ainda que nem sempre de forma positiva, essa urgência em se falar, pensar e problematizar fornece uma sensibilidade distinta, uma postura favorável, um passo significativo no sentido de entendimento e aceitação.

Zygmunt Bauman contribui para nossa discussão e procura oferecer contornos a essa sociabilidade moderna, balizada para além dos paradigmas, em um exercício de superação que exige uma resignificação de concepções tradicionais nas práticas cotidianas. O sociólogo não se refere a essa nova etapa de desenvolvimento como pós-moderna, mas utiliza outro termo: Líquida. A expressão identifica o caráter de mudanças a serem empreendidas, identificadas pela volatilidade e inconsistência das relações humanas, ou pela impossibilidade de se permanecer fixo, em outras palavras, "Ser moderno significa estar em movimento. É colocado em movimento ao se ser lançado na espécie de mundo dilacerado entre a beleza da

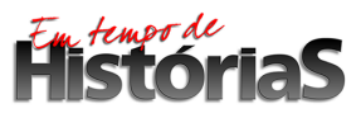


visão" (BAUMAN, 1999:92). Em sua análise do social, Bauman percebe a contemporaneidade como parte da própria modernidade, porém, sem ilusões, agravada pelo fenômeno da globalização e de suas implicações.

É se colocado em movimento ao se ser lançado na espécie de mundo dilacerado entre a beleza da visão e a feiura da realidade, realidade que se enfeou pela beleza da visão. Nesse mundo todos os habitantes são nômades, mas nômades que perambulam a fim de se fixar. Além da curva existe, deve existir, tem que existir uma terra hospitaleira em que se fixar, mas depois de cada curva, surgem novas curvas, com novas frustrações e novas esperanças ainda não destroçadas. (BAUMAN, 1999:92)

Diante desse panorama os agrupamentos tem se organizado estrategicamente não para impedir os conflitos oriundos das transformações do tempo moderno, mas elaborando táticas que seguirão inventando e reinventando o cotidiano.

Do palco à página, da prática aos campos intelectuais, gênero e sexo ganham status de linhas de pesquisa como estudo interdisciplinar que procura compreender as relações de transgeneridade na cultura e sociedade humana. Embora muitas vezes compreendidos como sinônimos foram utilizados separadamente para enfatizar a distinção entre a condição biológica determinante do sexo e as construções sociais que os envolvem.

De forma pioneira, a Antropologia e a Psicanálise adotaram o gênero como foco de investigação científica, tomando o homem e a mulher enquanto construção social, referendados por uma clara distribuição de papéis destinados a cada um.

Ao se popularizar enquanto campo disciplinar, as especulações sobre a validade de se pensar a partir de um gênero tomado como ponto de referência em detrimento de quaisquer outros esquecendo as relações que são, portanto, construídas, lançaram um novo olhar à temática, fazendo surgir à necessidade de uma forma de produção acadêmica que problematize esse diálogo entre os sexos, em contraponto a uma investigação que tome baliza parâmetros universais de análise.

Conforme mostram os exemplos práticos de escrita supostamente "própria" às mulheres, o essencial é deslocar a atenção, para apoiá-la nos usos sexualmente diferenciados dos modelos culturais comuns aos dois sexos. Desta forma, não se contentar com um diagnóstico prematuro caracterizando uma especificidade a partir de uma diferença, mas definir a natureza e o assento desta diferença que, mesmo marcando a prática feminina, pode encontrar sua razão num código de comportamento partilhado pelos dois sexos. (CHATIER, 1995: 39) 
Em tempos de pós-modernidade ou modernidade líquida, o debate entre masculino e feminino desdobrou-se em novos questionamentos e posicionamentos, apenas revelando o outro de forma multifacetada e plural, para além de dogmas e convenções de outrora. Como afirma Hall, "o sujeito, previamente vivido como tendo uma identidade unificada e estável, está se tornando [cada vez mais] fragmentado; composto não de uma única, mas de várias identidades, muitas vezes contraditórias e não resolvidas" (HALL, 2001: 12).

É um desafio definir os diferentes fenômenos ligados à sexualidade, seria mesmo um erro tentar etiquetá-los dentro de qualquer construção teórica dada sua pluralidade, porém, o primeiro passo à aceitação é o entendimento, não apenas tolerar, como um protocolo de civilidade, mas se definir, igualmente, a partir da diferenciação em relação à alteridade, àquilo que lhe escapa e que lhe define.

Apesar de ter sido deixada tradicionalmente nas mãos das mulheres, a
reflexão sobre gênero, na verdade, trata de uma estrutura de relações e,
portanto, diz respeito a todos, esclarecendo-nos sobre os meandros das
estruturas de poder e os enigmas da subordinação voluntária em geral, além
de originar um discurso elucidador sobre a implantação de outros arranjos
hierárquicos na sociedade, ao nos permitir falar sobre outras formas de
sujeição, sejam elas étnicas, raciais, regionais ou as que se instalam entre os
impérios e as nações periféricas. (SEGATO, 1998: 02)

Existem diferentes interpretações da Ciência e distintos protocolos sociais e médicos em constante desenvolvimento que concebem produtivas contendas, nem sempre esclarecedores, porém, ainda acenam como tentativas de compreensão daquilo que a tantos ainda evade.

O indivíduo não apenas direciona seu olhar à alteridade, mas volta-se para a contemplação do próprio eu, do próprio corpo, práticas responsáveis pela criação de novas representações e representações engendrando novas práticas. Não que o corpo fosse até então objeto calado, mas torna-se, agora, portador de uma voz de autoridade.

Nos espaços da vida privada, o indivíduo permitia-se a algumas explorações, ainda que timidamente, cingido por uma sociedade conservadora e limitadora dos próprios prazeres. Porém, a reconfiguração do real ecoou de forma gritante certos impulsos e anseios, trouxe para o campo público desejos reprimidos, sentimentos velados, tornou tema de debate, para além do íntimo, tabus de outrora que ganharam status de cientificidade acadêmica.

Os agentes sociais pressionaram os espaços ainda resistentes e a sociedade, os mais apegados a dogmas e tradições, enxergam o clamor da pluralidade humana em suas mais variadas expressões, culturais, sociais, étnicas e sexuais. 
Certamente, a tensão entre relatividade e universalidade das experiências humanas trazidas pela Antropologia, e própria da disciplina, alavancaram os estudos de gênero, abrindo caminho para uma discussão mais madura e comprometida, em particular, na grande explosão do conceito de cultura, que reverberou em outros campos do saber, especialmente na chamada História Cultural.

O estudo da cultura tem se desenvolvido, sem dúvida, como se essa máxima fosse seguida. A ascensão de uma concepção científica de cultura significava, ou pelo menos estava ligada a, a derrubada da visão da natureza humana dominante no iluminismo - uma visão que o que quer que se possa falar contra ou a favor, era ao mesmo tempo clara e simples - e sua substituição por uma visão não apenas mais complicada, mas enormemente menos clara. A tentativa de esclarecê-la de reconstruir um relato inteligente do que é o homem, tem permeado todo o pensamento científico sobre a cultura desde então. Tendo procurado a complexidade e a encontrado numa escala muito mais grandiosa do que jamais imaginaram, os antropólogos embaralharam-se num esforço tortuoso para ordená-la. E o final ainda não está à vista. (GEERTZ, 1978:25)

Consideramos que as desconstruções socioculturais e políticas da segunda metade do século XX, juntamente com as pesquisas sobre as noções de cultura provenientes, sobretudo da Antropologia, refletiram no fazer dos historiadores ao teorizarem suportes distintos por meio da releitura desses trabalhos.

Foram às mudanças sociais e a emergência de um novo sentir que impulsionaram a uma revisão acadêmica no modo de construção do saber histórico, voltado, até então, em grande parte, para os modelos teóricos globalizantes, com tendências a totalidade, nos quais o pesquisador era refém de uma busca pela verdade. Essas explicações, por sua vez, impossibilitavam a emergência de outros agentes que cada vez mais reivindicavam um lugar de fala. Como ressalta Ronaldo Vainfas, era preciso uma modificação em sua abordagem, uma alteração que priorizasse a complexidade do real, ou seja,

... Uma história problematizadora do social, preocupada com as massas anônimas, seus modos de viver, sentir e pensar. Uma história com estruturas em movimento, com grande ênfase no mundo das condições de vida material, embora sem qualquer reconhecimento da determinância do econômico na totalidade social, à diferença da concepção marxista da história. Uma história não preocupada com a apologia de príncipes ou generais em feitos singulares, senão com a sociedade global, e com a reconstrução dos fatos em série passíveis de compreensão e explicação. (VAINFAS, 2002: 17) 
Dessa forma, a chamada Nova História Cultural interessa-se pelos sujeitos produtores e receptores de cultura, ou seja, os meios e suporte através dos quais essa se reproduz e se transmite: as práticas e os processos. As visões de mundo, os sistemas de valores, os sistemas normativos que disciplinam os indivíduos, os modos de vida relacionados aos vários grupos sociais, as concepções relativas a esses grupos, as ideias disseminadas pelas várias tendências e correntes.

Destarte, ainda são reproduzidas, por distintos veículos, teorias que atribuem determinadas capacidades e habilidades inatas a agrupamentos particulares, reforçando comportamentos excludentes. Para os antropólogos, e outros campos especializados do saber, as diferenças genéticas não são determinantes das diferenças de uma cultura. Qualquer indivíduo está apto a receber uma dada herança cultural e, assim, desenvolver um comportamento baseado em aprendizado, um processo chamado de endoculturação.

A espécie humana se diferencia anatomia e fisiologicamente através do diformismo sexual, mas é falso que diferenças de comportamento existentes entre as pessoas de sexos diferentes sejam determinadas biologicamente. A antropologia tem mostrado que muitas atividades atribuídas às mulheres em uma cultura podem ser atribuídas aos homens em outra. (BARROS, 2000:19)

Dentro dessa perspectiva, tanto os corpos, sua estrutura física e material, ou seja, a carga genética, quanto às identidades, construções subjetivas, não são dados inexoravelmente ditados pela natureza, mas produção contextualizada. Tanto o corpo, quanto a relação de identificação forjada em relação a ele são feitos rotineiramente, em um espaço de permissões, restrições e concessões.

Nenhuma identidade ou essência pode ser edificada de forma anterior à performance, como já teria pronunciado e escandalizado há algum tempo atrás, Simone de Beauvoir, é sendo mulher que se torna mulher. Juntamente com o corpo, o gênero fornece ao indivíduo sua identidade social.

Tomar a condição biológica como constituinte dos gêneros masculino e feminino leva à desconstrução do corpo como algo arquitetado na e pela cultura, pois rompe com a sua visão de naturalização, colocando-o como objeto de estudo que pode ser observado, analisado, classificado, explicado e, normalizado. Essa normalização ao que excede, ou seja, o tratamento ao que é tido como desvio do padrão, leva a um processo de estigmatização e negação da alteridade, da diferença. 
O negativamente estigmatizado é encarado como pessoa que está inabilitada para a aceitação social plena; um indivíduo que poderia ter sido facilmente recebido na relação social cotidiana possui um traço que se pode impor à atenção e afastar aqueles que ele encontra, destruindo a possibilidade de conhecimento de outros atributos seus. (ARAÚJO 2004:15)

Em meados da década de 1970 os avanços na área médica e da cirurgia plástica aliada às teorias sobre Genitais e Criação, Natureza e Cultura, levaram à elaboração de protocolos médicos de manipulação cirúrgica no sentido reparação de crianças intersexo. A invasão consistiria em um método de conciliar aparência a uma suposta essência, ou seja, moldar genitais a fim de adquirirem uma anatomia apropriada aos padrões comumente estabelecidos e aceitos dentro da normalidade da época.

Dentre os principais defensores dessas intervenções, convertendo-se em porta-voz dominante quanto aos estudos de gênero, defendendo a identidade como algo exclusivo de criação e da socialização, o médico Jonh Money, da Universidade John Hopkins, teorizou e forneceu uma alternativa de reparação a fim de solucionar a emergência social causada pelo nascimento de bebês intersexuados.

É necessário frisar, que a própria existência de indivíduos excluídos da rígida dicotomia entre macho e fêmea lança questionamentos profundos nas estruturas religiosas e legais e, na grande maioria dos casos, a cirurgia de reparação e conserto confere um ar científico a uma necessidade preconceituosamente associada a um distúrbio biológico, uma anomalia.

Cada ser humano tem múltiplas formas de vivenciar sua identidade, e isso não muda para as pessoas transgênero: não são todas iguais. A identidade de gênero não esgota a subjetividade de uma pessoa, nem sua subjetividade se restringe ao fato de ser transexual. (JESUS, 2012: 12)

O aparente sucesso do Protocolo Money, forjado pelo não revelar de suas cobaias, veio à tona anos mais tarde, demonstrando a instabilidade de suas ideias. Os ativistas sexuais e os estudos recentes além de demonstrarem dúvidas sobre a maneira total das práticas cirúrgicas, revelam uma guinada quanto à confiabilidade inabalável da teoria de que a identidade de gênero está determinada pelos genitais ou pela educação, causando uma transformação paradigmática no pensamento global da comunidade científica.

O que nos é revelado é a busca desenfreada por uma adaptação da fisiologia ao dimorfismo sexual, ainda que por intervenções mutiladoras do físico e da alma, ou seja, o corpo tido como matéria plástica, flexível e sujeita às convenções sociais. 
É necessário frisar o trauma gerado por essas intervenções médicas, em grande parte, mantidas em segredo e apenas reveladas aos pacientes em fase adulta, ou seja, além da notícia desconcertante sobre sua condição fisiológica e biológica original, as vítimas ainda precisam lidar com um processo de reconstrução do próprio eu, com a dificuldade de se reposicionar frente à sociedade a si mesmo, lidar com o sentimento de uma decisão que lhe foi imposta, de forma abrupta e violenta, uma identidade e um direito que lhe foi roubado.

O questionamento dos tratamentos validados como sucesso irrefutável por Jonh Money, não demonstrou de forma simplista a revolta da natureza sob a biologia ou a psicologia, mas coloca em questão o limite de adaptação do corpo às imposições que lhe são dadas, na grande maioria das vezes, de forma pouco conciliatória e traumática.

Criar meninos e meninas não os transforma necessariamente em homens e mulheres adaptados às convenções ao qual se sujeitaram, não significa uma genuína inserção ao meio ao qual foram educados e moldados. É preciso considerar o papel ativo dos indivíduos nesse processo, não como matérias inertes à mercê das convenções sociais e culturais, mas agentes atuantes e contestadores da realidade à sua volta.

Tomando como mote central o conceito de cultura e admitindo sua relevância para a análise de como em "diferentes lugares e momentos uma determinada realidade social é pensada, dada a ler;" (CHARTIER, 1990: 16) a História Social da Cultura, renovada pelas contribuições das Ciências Sociais, pretende colocar em ênfase seus objetos e conferir primazia a forma como os construímos ao estabelecer relações entre os acontecimentos.

É errôneo supor que o consumo das ideias, valores e artigos pelos sujeitos em seus afazeres diários se dê de forma passiva, uniforme e adequada ao conformismo do mercado e dos poderes sociais, ao contrário, trata-se de uma relação de produção e circulação, em que estão previstas apropriações e resignificações.

Nas análises de Michel De Certeau, o interesse pelo outro define uma perspectiva epistemológica e um método. A procura pela compreensão do inteligível dentro de um discurso social e histórico específico nos leva ao território da diferença e da alteridade, rompendo o mundo calmo das certezas e normalizações.

Pensamos a noção de apropriação a partir das formulações de Roger Chartier, tomadas de empréstimo de Michel De Certeau, para definir o consumo cultural como uma operação de produção que, embora não fabriquem nenhum objeto, assinala a sua presença a partir das maneiras de utilizar os produtos que lhes são impostos, ou seja, um contraponto às operações que visam apenas discipliná-lo e regulamentá-lo. 
Devemos observar que os responsáveis pela elaboração das mensagens e imagens não o fazem de forma fechada e padronizada que serão decodificadas de maneira uniforme por todos os receptores, nem que tais enunciados não se ancorem em pressupostos comuns, capazes de conduzir a variadas interpretações. No entanto, é a partir das situações dialógicas que os debates são construídos e as identidades sociais forjadas.

As representações do mundo social assim construída, embora aspirem à universalidade de um diagnóstico fundado na razão, são sempre determinadas pelos interesses de grupos que as forjam. Daí, para cada caso, o necessário relacionamento dos discursos proferidos com a posição de quem os utiliza. (CHARTIER, 1990:16)

Roger Chartier demonstra uma abertura nos modos de observação da fabricação e circulação dos bens produzidos por uma determinada sociedade, afirmando que esses produtos não são simplesmente aceitos passivamente; não são recebidos como uma herança perpetuada por uma tradição; existe, pois, um processo de recepção e de apropriação que não podem ser negligenciados. Cada espaço é, pois, dotado de uma inteligibilidade própria, permeando por normas, interesses, valores e princípios morais e éticos.

As percepções do social não são de forma alguma discursos neutros: produzem estratégias e práticas (sociais, escolares, políticas) que tendem a impor uma autoridade à custa de outros, por elas menosprezados, a legitimar um projeto reformador ou a justificar, para os próprios indivíduos, as suas escolhas e condutas. (CHARTIER, 1990: 17)

Assim, os indivíduos, independente de sua condição biológica ou sexual, constroem suas identidades em constante processo de disputas e concessões. Não há garantia em uma educação que impossibilite desvios e percursos alternativos ao que se tentou inicialmente instituir. Os caminhos podem ser escolhidos apesar de todo um processo de reafirmação de determinados padrões sociais, ou seja, ainda que haja uma imposição familiar, escolar, religiosa, cultural e social, os agentes sociais são responsáveis por novas adaptações e rearranjos, não negligenciando a força das convenções, mas reforçando sua condição de resistência. Se os gêneros são construídos socialmente, um menino ou menina pode não necessariamente se identificar com esses padrões, pois o corpo foge a essas convenções.

Os impulsos e tensões sexuais e a forma como essas relações são criadas refletem particularidades que a regra plastifica, seleciona, observa e repara, mas que não normaliza, visto que essa naturalização não é possível. 
Assim, o grande desafio é a aceitação da pluralidade, do entendimento do outro a partir de suas várias adaptações, resultado de um processo longo de experimentação e reação. Se o discurso de padronização preconizado de forma dogmática pela modernidade não conduziu o homem ao estado de felicidade e ordem prometido pelos avanços científicos e tecnológicos de até então, talvez a reconciliação com próprio eu acene como o caminho mais viável nesse alvorecer de novo século.

\section{Referências Bibliográficas}

ARAÚJO, Fernanda Carolina de. Os Estabelecidos e os Outsiders: Sociologia das Relações de poder a partir de uma pequena comunidade. Resenha. Revista Liberdades. [online]. Disponível em: http://www.revistaliberdades.org.br/site/outrasEdicoes/outrasEdicoesExibir.php?rcon_id=96.

BARROS, Roque Laraia. Cultura, um conceito antropológico. Rio de Janeiro: Jorge Zahar, 2004.

BAUMAN, Zygmunt. Modernidade e Ambivalência. Ed. Zahar, Rio de Janeiro, 1999.

BEAUVOIR, Simone de. O Segundo Sexo, v.I, II. Tradução Sérgio Milliet. Rio de Janeiro: Nova Fronteira, 1980.

CERTEAU, Michel de. A Invenção do Cotidiano, Artes de Fazer. Trad. Ephraim Ferreira Alves, Rio de Janeiro, Ed. Vozes, 2008.

CHARTIER, Roger. Diferenças entre os sexos e dominação simbólica. Cadernos Pagu, Unicamp, n. 4, 1995. [online]. Disponível em: <http://www.pagu.unicamp.br/files/cadpagu/Cad04/pagu04.04.pdf>.

Lisboa: Difel, 1990. A História Cultural: entre práticas e representações. Trad. Maria Manoela Galhardo.

GEERTZ, C. A Interpretação das Culturas. Rio de Janeiro: Zahar, 1978.

HALL, Stuart. "A produção Social da Identidade e da Diferença”. In: Tomáz Tadeu da Silva (org). Identidade e Diferença: a perspectiva dos estudos culturais. Rio de Janeiro: Vozes, 2000.

HARVEY, David. A Condição Pós-Moderna. 14 ed. São Paulo, Loyola, 2005.

NIETZSCHE, Friedrich. Aurora. Trad. Antonio Carlos Braga. São Paulo: Editora Escala, 2007.

JESUS, Jaqueline GOMES DE. Orientações sobre identidade de gênero: conceitos e termos. Guia Ténico sobre pessoas transexuais, travestis e demais transgêneros, para formação de opinião. $2^{\mathrm{a}}$ Ed. Brasília, 2012.

PESAVENTO, Sandra Jatahy. História e Literatura: uma nova-velha história. [online]. Disponível em: http://www.teoriahistoria.blogspot.com/.../historia-literatura-uma-velha-nova.html.

SEGATO, Rita Laura. Os percursos do gênero na Antropologia e para além dela. Série Antropológica 236. Brasília, 1998.

VAINFAS, Ronaldo. Os protagonistas anônimos da história. São Paulo, SP: Campus, 2002. 